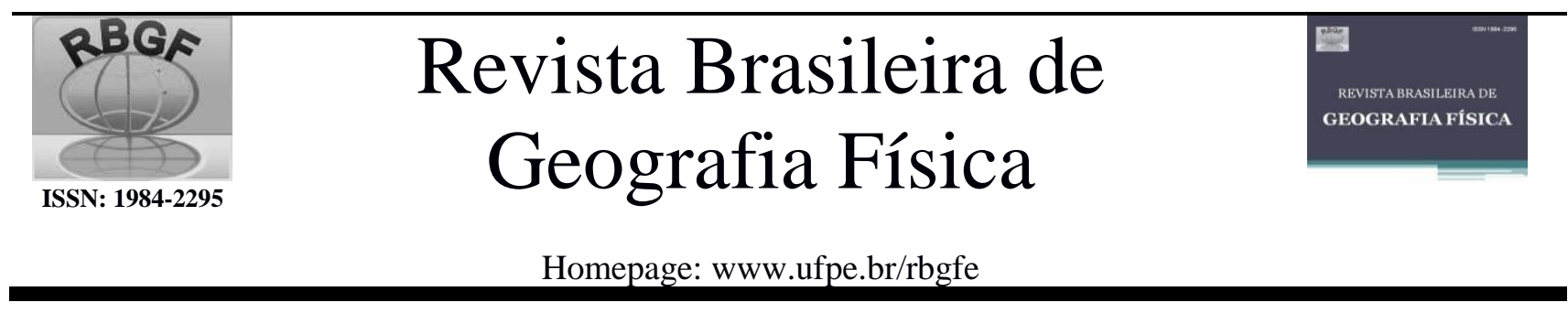

\title{
Fenologia da Salicornia neei Lag. cultivada no semiárido cearense ${ }^{1}$
}

\author{
Paulo Ricardo Alves², Eliseu Marlônio Pereira de Lucena³, Oriel Herrera Bonillaª , César Serra Bonifácio \\ Costa $^{5}$
}

\begin{abstract}
${ }^{1}$ Parte da pesquisa de Mestrado, executada pelo primeiro, orientada pelo segundo e coorientada pelo terceiro autor, no âmbito do Mestrado Acadêmico em Recursos Naturais na Universidade Estadual do Ceará, Fortaleza, CE.

${ }^{2}$ Mestre, Mestrado Acadêmico em Recursos Naturais, Universidade Estadual do Ceará, Campus Itaperi, CEP 60.714-903, Fortaleza, CE. E-mail: pa9910@gmail.com - autor correspondente.

${ }^{3}$ Doutor, Professor Associado do Curso de Ciências Biológicas e do Mestrado Acadêmico em Recursos Naturais, Universidade Estadual do Ceará, Campus Itaperi, CEP 60.714-903, Fortaleza, CE. E-mail: eliseu.lucena@uece.br.

${ }^{4}$ Doutor, Professor Associado do Curso de Ciências Biológicas e do Mestrado Acadêmico em Recursos Naturais, Universidade Estadual do Ceará, Campus Itaperi, CEP 60.714-903, Fortaleza, CE. E-mail: oriel.herrera@uece.br.

${ }^{5}$ Doutor, Professor Titular do Instituto de Oceanografia e do Programa de Pós-Graduação em Aquicultura, Universidade Federal do Rio Grande, Campus Carreiros, CEP 96.203-900, Rio Grande, RS. E-mail: costacsb@ hotmail.com.
\end{abstract}

\section{R E S U M O}

Artigo recebido em 26/01/2019 e aceito em 23/04/2019

A halófita Salicornia neei Lag. apresenta ciclo de vida perene e elevada tolerância à salinidade intersticial. Este trabalho objetivou caracterizar a fenologia e as exigências térmicas da Salicornia neei Lag. cultivada no semiárido cearense. O monitoramento ocorreu em área de cultivo de $200 \mathrm{~m}^{2}$ em Ocara-CE, semiárido cearense. Foram marcadas 20 plantas aleatoriamente ( 10 femininas e 10 masculinas), e irrigadas uma vez ao dia por 30 minutos. Foram observadas as fenofases de enfolhamento, queda foliar, floração e frutificação, no período de junho de 2014 a maio de 2015. O enfolhamento predominou durante todo o período monitorado, e apresentou uma baixa intensidade de queda foliar. A floração ocorreu de setembro de 2014 a março de 2015, e a frutificação ocorreu de setembro de 2014 até abril de 2015. Os resultados indicaram que a energia exigida por $S$. neei desde a marcação da planta até a flor em antese foi de 1.139,2 unidades de calor (UC). Para a frutificação, a partir da flor em antese até o estádio de fruto maduro foi de 1.282,4 UC. Conclui-se que a $S$. neei teve uma boa adaptação ao semiárido, alcançando todas as fenofases de seu ciclo perene, com uma irrigação diária. A falta de sincronia na floração e frutificação dificulta a colheita das plantas quando maduras, podendo induzir a erros, levando a uma subestimativa na produção de flores e frutos quando estimadas.

Palavras-chave: Fenofase, vegetação halofítica, salinidade.

\section{Phenology of the Salicornia neei Lag. Cultivated in Ceara Semiarid}

\section{A B S T R A C T}

The Halophyte Salicornia neei Lag. features perennial life cycle and high tolerance to salinity of interstitial. This work aimed to characterize the phenology and the thermal requirements of Salicornia neei Lag. grown in the semiarid. The monitoring occurred in growing area of $200 \mathrm{~m}^{2}$ in Ocara-CE, Ceara semiarid. 20 plants were marked at random (10 female and 10 male), and irrigated once a day for 30 minutes. Observed the phenophases of leafiness, fall foliage, flowering and fruiting in the period June 2014 to May 2015. The leafiness prevailed throughout the period monitored, and presented a low intensity of leaf fall.Flowering occurred September 2014 and March 2015, and fruiting occurred September 2014 until April 2015. The results indicated that the energy required by S. neei since marking of the plant until the flower anthesis was 1,139.2 heat units (HU). For the fruiting, from the flower anthesis until the mature fruit stage was of 1,282.4 HU.It is concluded that $S$. neei had a good adaptation to the semi-arid, reaching all the phenophases of your perennial cycle, with a daily irrigation. The lack of synchrony on flowering and fruiting difficult to harvest plants when mature, and may induce errors, leading to an underestimate in the production of flowers and fruit when estimated.

Keywords: Phenophase, halophytic vegetation, salinity.

\section{Introdução}

As halófitas representam o único grupo de plantas capazes de viverem em solos com elevadas concentrações de sais (Taiz e Zeiger, 2013). O cultivo de halófitas é uma alternativa sustentável para o aproveitamento de áreas do semiárido sujeitas à salinização do solo. O Brasil possui uma rica flora de halófitas com grande potencial 
biotecnológico e econômico para produção de alimentos e de substâncias bioativas (Costa e Herrera, 2016).

As halófitas, devido a suas altas taxas de acumulação e absorção de sais nos tecidos, sobretudo na parte aérea, possuem habilidade de removerem sais do solo. A fitorremediação consiste em uma eficiente técnica de recuperação de solos salinos e sódicos tanto pela remoção considerável de sais quanto pela melhoria da estruturação do solo bem como $\mathrm{n}$ incremento da atividade biológica quando as plantas são introduzidas em áreas sem cobertura vegetal (Freire et al., 2010).

A halófita Salicornia neei é uma espécie nativa sul-americana e era anteriormente chamada de Salicornia gaudichaudiana Moq. e Sarcocornia ambigua (Michx.) M.A. Alonso \& M.B. Crespo (Doncato, 2017; Costa et al., 2018). É uma halófita da região costeira que cresce em solos com salinidade intersticial elevada (16 a $55 \mathrm{dS} \mathrm{m}^{-1}$ ) (Costa e Neves, 2006).

Esta halófita pertence à classe Equisetopsida, subclasse Magnoliidae, à ordem Caryophyllales, à família Amaranthaceae, ao gênero Salicornia e à espécie Salicornia neei (Tropicos, 2019).

As folhas apresentam vértice arredondado a subagudo. Possui estruturas florais reduzidas, com inflorescências $(150 \times 4 \mathrm{~mm})$ dispostas em um ponto terminal no ápice das brácteas. Suas sementes possuem diâmetro de 1,4 x $0,9 \mathrm{~mm}$ e são cobertas em seus bordos por tricomas (50 a $95 \mu \mathrm{m})$. $\mathrm{O}$ sistema radicular produz poucas ramificações $\mathrm{e}$ tende a ser superficial, muitas vezes penetrando menos de 10-20 cm no solo (Alonso e Crespo, 2008).

Esta halófita apresenta-se na forma de haste (caule) suculenta com altura máxima de 50 $\mathrm{cm}$, ereta ou decumbente, de forma cilíndrica e segmentada, correspondendo aos pares de folhas fusionadas sobre a haste. Apresentam-se hastes de cores verde e avermelhadas, estas últimas devido à presença de betacianina (Alonso e Crespo, 2008).

Os caules e as sementes dessa espécie apresentaram elevada qualidade nutricional, com altos teores de minerais, tais comoK, $\mathrm{Mg}$, Ca e $\mathrm{Zn}$ (Bertin et al., 2014; 2016); de ácido palmítico e ácidos graxos poli-insaturados, principalmente o ácido linoléico, um $\omega-6$, e o ácido oléico, um $\omega-9$ (Bertin et al.,2014; Costa et al., 2014); além de compostos fenólicos compropriedades antioxidantes e anti-inflamatórias (Bertin et al., 2014; Timm et al., 2015).

Por apresentar ciclo de vida perene, a $S$. neei pode sobreviver por vários anos, podendo ser propagada por sementes ou através de crescimento vegetativo, devido à sua capacidade caulinar de rebrotamento após a poda (Costa e Neves, 2006).

A produção de biomassa e subprodutos da S. neei permite a utilização de áreas antes não exploradas, contribuindo para a preservação de mananciais de água doce. Águas de poços salinos, rejeitos salinos de dessalinizadores, efluente salino da carcinicultura ou mesmo água do mar podem ser bombeados para cultivos em áreas desérticas e semiáridas, que passam a ser fixadoras de carbono da atmosfera e geradoras de biomassa (Ruana et al., 2008; Costa, 2011).

O plantio de cada safra é um custo operacional de difícil redução nesta espécie, sendo necessários cuidados contra a dessecação para evitar grandes mortalidades nos períodos de germinação e estabelecimento (enraizamento) das plantas (Leite et al., 2007).

Estudos envolvendo as estratégias de sobrevivência das espécies Sarcocornia e Salicornia em diferentes ambientes, níveis de salinidade e técnicas de cultivo, têm sido realizados, visando o interesse no reconhecimento de suas estruturas morfo-anatômicas, da composição química e distribuição de seus componentes na estrutura celular, a fim de prospectar amplamente a cultura biosalina das mesmas (Porto et al., 2006; Parida e Jha, 2010; D'oca et al., 2012).

A fenologia é o estudo dos eventos periódicos que formam o ciclo de vida dos organismos sendo esses estudos fundamentais para compreender o mecanismo de funcionamento da espécie dentro da comunidade (Nielsen et al. 2016), pois dessa forma é possível perceber o momento em que há disponibilidade de recursos e podem acontecer as diversas interações da planta com suas espécies dependentes: herbívoros, parasitas e polinizadores (Ferreira e TorezanSilingardi, 2013).

As fases fenológicas de uma planta sofrem variação de acordo com as condições climáticas, sendo precipitação e temperatura do ar os fatores que causam mais efeitos (Scoriza e PiñaRodrigues, 2014).

A fenologia de $S$. neei cultivada no semiárido ainda é insipiente. Dessa forma, os estudos fenológicos possibilitam a determinação das exigências climáticas da planta, dando suporte ao planejamento de manejo e estimativa da possível data de colheita do fruto (Roberto et al., 2005; Busato et al., 2013). De acordo com Berilli et al. (2007), o estudo da taxa de crescimento dos frutos tem grande importância para o conhecimento das diferentes fases fenológicas envolvidas no seu desenvolvimento, como a época de início da maturação para definir os períodos de colheitas. 
Conhecer as necessidades térmicas do desenvolvimento vegetativo (emissão de folhas) e do reprodutivo é fundamental para a otimização das estratégias de manejo, melhoramento da produção e da qualidade de mudas, auxiliando em programas de seleção e melhoramento, bem como, na escolha das espécies ou cultivares mais adaptadas às condições climáticas do local de cultivo (Müller et al., 2009; Martins et al., 2012).

Uma forma muito utilizada para estimar o tempo necessário para o avanço fenológico é o uso das unidades térmicas (graus-dia), que representa a necessidade de energia, acima da condição mínima e abaixo da máxima exigida pela planta (Rodrigues et al., 2013). Os graus-dia tem como base o acúmulo térmico diário dentro dos quais a planta se desenvolve, estes são delimitados pelas temperaturas basais superior (TB) e inferior $(\mathrm{Tb})$ de cada espécie (Müller et al., 2009).

Ambas as temperaturas base (TB e $\mathrm{Tb}$ ) representam, respectivamente, a temperatura acima e abaixo da qual o desenvolvimento é nulo ou desprezível para fins de cálculo. Geralmente, a TB assume valores elevados, os quais dificilmente são atingidos durante o ciclo de desenvolvimento no campo (Müller et al., 2009). Já a Tb assume valores baixos, os quais ocorrem principalmente durante $\mathrm{o}$ inverno, sendo bastante utilizada na clássica equação de cálculo dos graus-dia, a qual é dada pela diferença entre a temperatura média do ar diária e a Tb da espécie (Rosa et al., 2009).

A predição do estádio de desenvolvimento baseada no acúmulo de graus $\left({ }^{\circ} \mathrm{C}\right)$ por unidade de tempo, acima da temperatura base, é frequentemente designada como "limiar para o crescimento". A temperatura limite é definida com base no tempo e na temperatura, desde o plantio até a colheita de uma cultura, desenvolvida em diferentes localidades ou durante vários anos. Determina-se a temperatura média diária, cuja soma algébrica é deduzida da temperatura mínima de crescimento. Assim, pode-se predizer a época provável da maturidade, num determinado ano. À medida que a maturidade avança, ela pode ser confirmada por outros métodos (Chitarra e Chitarra, 2005).

Com o intuito de contribuir com os projetos de cultivo de plantas halófitas nativas de ampla distribuição na costa brasileira, em solos salinizados e/ou utilizando efluentes salinos em outras áreas do semiárido brasileiro, permitindo reduzir o grau de degradação, recuperando e preservando os ecossistemas nativos e favorecendo o setor de meio ambiente, bem como, avaliando a produtividade que pode ser alcançada pelas halófitas no semiárido e as suas limitações nutricionais que possam ocorrer em solos salinizados, a presente pesquisa objetivou caracterizar a fenologiae as exigências térmicas da Salicornia neei Lag. cultivada no semiárido cearense.

\section{Material e Métodos}

\section{Obtenção das plantas e área de cultivo}

Inicialmente, as mudas de $S$. neei foram propagadas por estaquia, a partir de fragmentos de caules vegetativos coletados em uma área de cultivo associado a um marisma artificial utilizado no tratamento de efluentes de viveiros de camarão no Centro de Estudos Ambientais CosteirosCEAC, da Universidade Federal do Ceará-UFC,

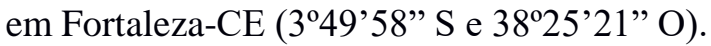

Foram utilizados ramos com bases lignificadas, os quais demonstram melhor resposta de brotamento vegetativo (Greis, 2009). No laboratório os ramos passaram por triagem para corte e estaquia. Os cortes para a propagação foram feitos nos entrenós dos ramos, com parte vegetativa verde, ereta e nós preservados, nos quais as raízes das estacas se desenvolveram.

Os segmentos vegetativos cortados foram plantados em bandejas semeadeiras de isopor com substrato formado por areia e composto orgânico (1:1), e colocadas em viveiro alagado sob um telado com $50 \%$ de sombreamento.

Após oito semanas de cultivo nas bandejas e estabilização do estande, as mudas foram levadas para a área de cultivo localizada na Fazenda Canafístula, no município de Ocara-CE (429'27' $\mathrm{S}$ e $38^{\circ} 35^{\prime} 48^{\prime \prime} \mathrm{O}$ ), no semiárido cearense (Figura $1)$. 
Revista Brasileira de Geografia Física V. 12 N. 02 (2019) 489-504.
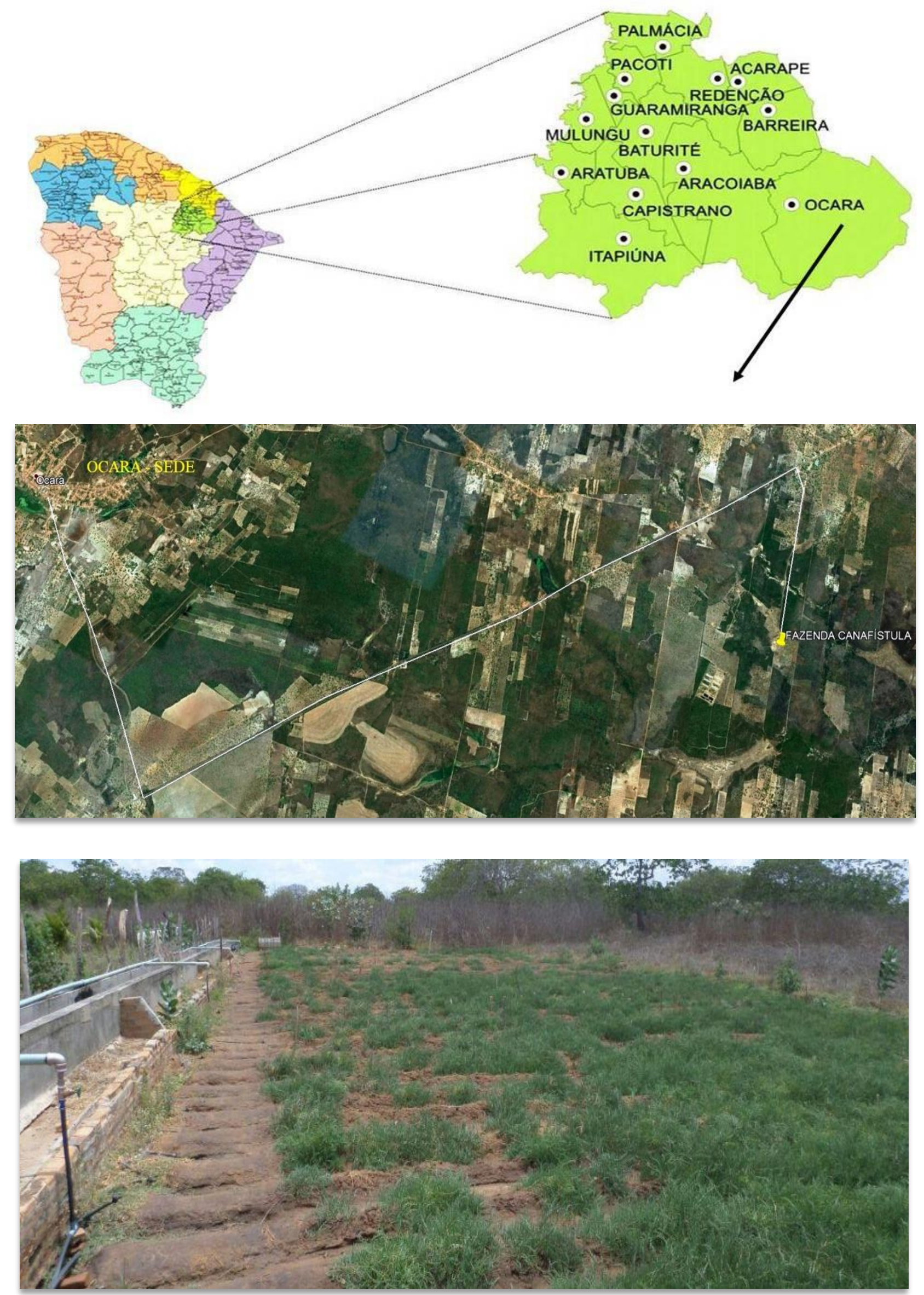

Figura 1. Localização geográfica do município de Ocara-CE e da área de cultivo de Salicornia neei Lag. Adaptado do IPECE (2016). 
Situado a uma elevação $170 \mathrm{~m}$ de altitude, onde o solo predominante da região é a Areia Quartzosa Distróficas, Planossolo Solódico e Podzólico Vermelho-Amarelo. O clima da região é Tropical com inverno seco (Aw), de acordo com a classificação climática de Koppen - Geiger (Muniz, 2017). A temperatura média é de 26 a $28^{\circ} \mathrm{C}$, com pluviosidade anual de $959,5 \mathrm{~mm}$ (IPECE, 2015).

O cultivo de $S$. neei no semiárido cearense ocorreu em uma superfície de $200 \mathrm{~m}^{2}$ preparada com sulcos a $0,5 \mathrm{~m}$ de distância entre si. Na parte superior do canteiro foi montado um sistema de irrigação por sulco para distribuição da água na área cultivada.

A água utilizada no sistema de irrigação foi bombeada por uma bomba submersa de $1,5 \mathrm{CV}$ de potência, a qual bombeava a água salina de poço profundo, com vazão de $300 \mathrm{~L} / \mathrm{h}$. As plantas eram irrigadas uma vez ao dia, durante 30 minutos (Figura 1). A água de irrigação apresentou salinidade alta $\left(\mathrm{C}_{4}\right)$ e baixo conteúdo de $\mathrm{Na}^{+}\left(\mathrm{S}_{1}\right)$ (Tabela 1).

Os dados climáticos referentes à temperatura mínima, máxima e média, bem como, precipitação pluviométrica do município onde o estudo foi realizado, foram fornecidos pela Fundação Cearense de Meteorologia e Recursos Hídricos-FUNCEME.

\section{Fenologia}

As fenofases foram observadas durante 12 meses numa amostra contendo 20 plantas as quais foram selecionadas aleatoriamente, sendo 10 plantas femininas e 10 plantas masculinas. Quinzenalmente foram observadas a presença de ramos vegetativos (enfolhamento e/ou queda foliar), floração e frutificação, no período de junho de 2014 a maio de 2015.

Após a marcação das plantas, aplicou-se a metodologia descrita por Lucena (2006), que consiste no monitoramento diário dos botões florais até a antese e em seguida realizou-se o monitoramento semanal das ocorrências de mudanças dos estádios da flor e do fruto. Os estádios de maturação dos frutos foram determinados de acordo com características externas, tais como: o formato e a coloração do fruto.

A intensidade dos eventos fenológicos apresentados em $S$. neei foi estimada seguindo-se os critérios de Fournier (1974). Foram registradas as seguintes fenofases:

1. Presença de botões florais no momento da observação;

2. Presença de flores parcialmente ou totalmente abertas;

3. Presença de frutos maduros ou imaturos, caídos ou não;

4. Presença de folhas parcial ou totalmente novas, ou não.

Cada fenofase foi registrada qualitativamente (presença ou ausência) e para estimar sua intensidade foi utilizado o percentual de intensidade de Fournier, que consiste em uma metodologia de quantificação fenológica proposta por Fournier (1974) na qual classifica por meio de uma escala intervalar semiquantitativa de cinco categorias ( 0 a 4), com intervalo de $25 \%$ de amplitude, onde:

$0=$ ausência da fenofase;

$1=$ presença da fenofase com magnitude de 1 a $25 \%$;

$2=$ presença da fenofase com magnitude de 26 a $50 \%$;

$3=$ presença da fenofase com magnitude de 51 a $75 \%$;

$4=$ presença da fenofase com magnitude de 76 a $100 \%$.

O percentual de intensidade de Fournier exige trabalho minucioso do observador, mas mostra os picos e tendências em cada fenofase observada, distinguindo vários níveis de intensidade. Este tipo de detalhamento das informações fenológicas é desejável em estudos populacionais e análises de correlação, como no estudo de Bencke e Morellato (2002).

Tabela 1. Análise físico-química da água de irrigação na área de cultivo em Ocara-CE.

\begin{tabular}{|c|c|c|c|c|c|c|c|c|c|c|c|}
\hline \multicolumn{5}{|c|}{ Cátions $\left(\mathrm{mmol}_{\mathrm{c}} \mathrm{L}^{-1}\right)$} & \multicolumn{3}{|c|}{ Ânions $\left(\mathrm{mmol}_{\mathrm{c}} \mathrm{L}^{-1}\right)$} & $\mathrm{CE}$ & SD & RAS & Classificação \\
\hline $\mathrm{Ca}^{2+}$ & $\mathrm{Mg}^{2+}$ & $\mathrm{Na}^{+}$ & $\mathrm{K}^{+}$ & $\Sigma$ & $\mathrm{Cl}^{-}$ & $\mathrm{HCO}^{3-}$ & $\Sigma$ & $\mathrm{dS} \mathrm{m^{-1 }}$ & $\mathrm{MG} \mathrm{L}^{-1}$ & & \\
\hline 15,9 & 18,2 & 9,9 & 0,9 & 44,9 & 44,2 & 0,1 & 44,2 & 4,45 & 4,450 & 2,39 & $\mathrm{C}_{4} \mathrm{~S}_{1}$ \\
\hline
\end{tabular}

CE - Condutividade elétrica; SD - Sólidos dissolvidos; RAS - Razão de adsorção de sódio. 


\section{Unidades de calor (graus-dia)}

As determinações de unidades de calor (UC) foram feitas de acordo com Chitarra e Chitarra (2005), onde se calculou a temperatura média diária, cuja soma algébrica foi deduzida da temperatura mínima de crescimento:

onde:

$$
\mathrm{UC}=\Sigma\left(\mathrm{T}_{\text {máx }}+\mathrm{T}_{\text {mín }} / 2\right)-\mathrm{T}_{\text {base }}
$$

$\mathrm{UC}=$ unidades de calor, ${ }^{\circ} \mathrm{C}$;

$\mathrm{T}_{\text {máx }}=$ temperatura máxima do ar, ${ }^{\circ} \mathrm{C}$;

$\mathrm{T}_{\text {mín }}=$ temperatura mínima do ar, ${ }^{\circ} \mathrm{C}$;

$\mathrm{T}_{\text {base }}=$ temperatura base para a planta, ${ }^{\circ} \mathrm{C}$.

A temperatura base adotada para Salicornia neei foi de $15^{\circ} \mathrm{C}$ devido à espécie estudada pertencer a um ambiente (Ilha da pólvora, RS) cujas condições meteorológicas apresentam poucas oscilações nas suas características, com média de temperatura mínima de $15,6^{\circ} \mathrm{C}$ durante todo o ano.
Tal característica é enfatizada no cultivo realizado por Izzepi (2011), no qual observou que o excesso de umidade durante o período de chuvas regulares e as menores temperaturas do outono prejudicaram o desenvolvimento de $S$. neei.

\section{Comprimento do dia}

A duração do dia astronômico (h) para os locais de estudo foi calculada segundo Tubelis e Nascimento (1992).

\section{Resultados e Discussão}

A Figura 2A demonstra as médias de temperatura anual no município de Ocara-CE, sendo observado que as maiores temperaturas ocorreram no mês de dezembro, com máximas chegando à $35^{\circ} \mathrm{C}$, e as menores temperaturas ocorreram no mês de fevereiro, com mínimas chegando à casa dos $20^{\circ} \mathrm{C}$. A Figura $2 \mathrm{~B}$ apresenta o comprimento médio do dia em horas em OcaraCE.
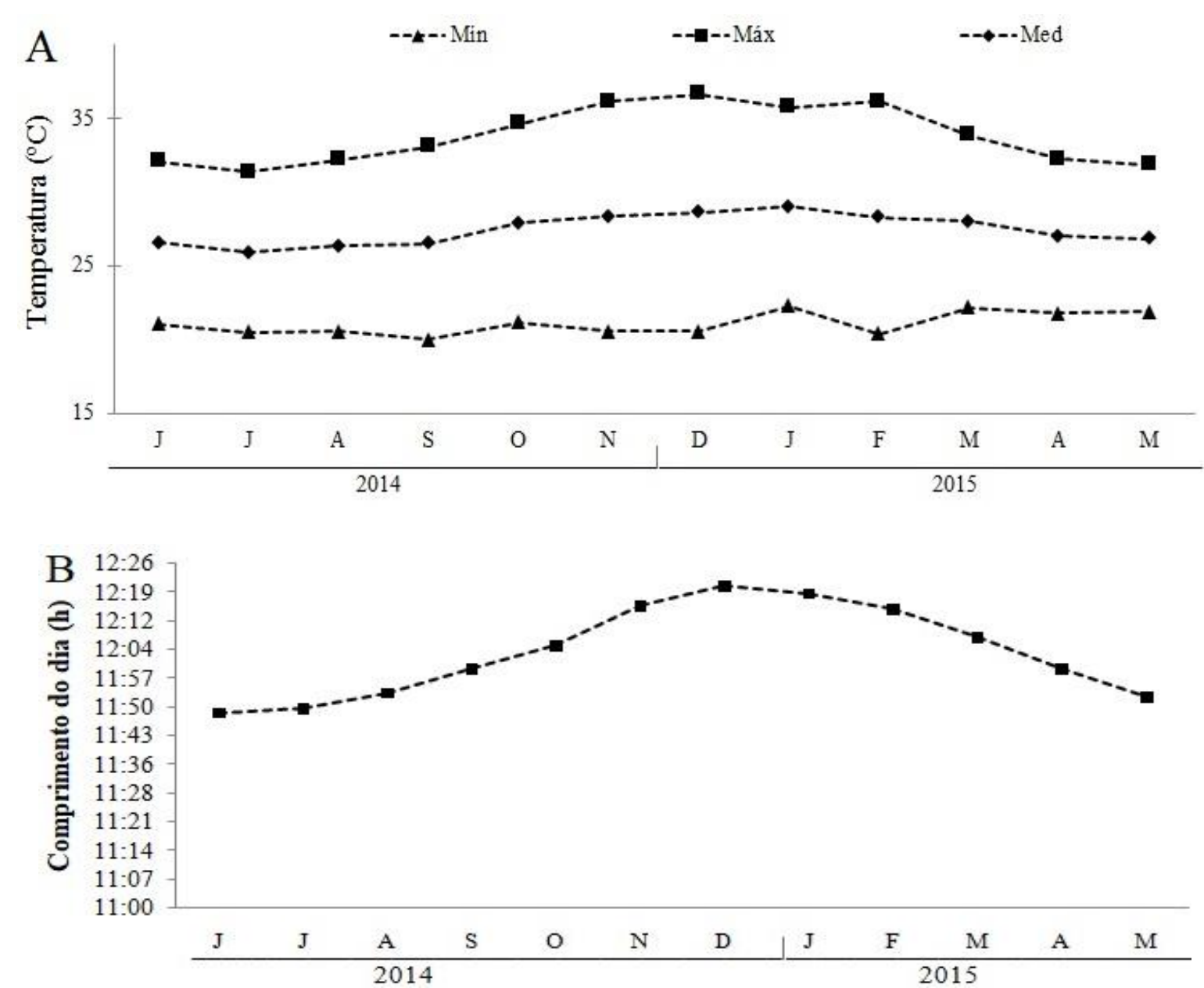

Figura 2. Temperaturas (A) e comprimentos do dia em horas (B) mensais durante a pesquisa em Ocara-CE. 
Fenofase vegetativa: folha jovem e folha madura

A fenofase de folha jovem esteve presente em todos os indivíduos monitorados. A intensidade de folhas jovens nas plantas femininas permaneceu constante de junho de 2014 até abril de 2015 (50\%), havendo um decréscimo apenas em maio de $2015(37,5 \%)$. Para as plantas masculinas as menores intensidades de folhas jovens ocorreram em julho e em dezembro de 2014 (25\%), enquanto as maiores ocorrências se deram entre setembro e outubro de 2014 e de janeiro a abril de 2015 (50\%) (Figura 3A).

O brotamento foliar é potencialmente limitado por um pequeno grupo de fatores abióticos: água, fotoperíodo, $\mathrm{CO}_{2}$ e minerais; e significativas mudanças sazonais em alguns desses fatores podem exercer uma força seletiva sobre o comportamento fenológico das plantas (Van Schaik et al., 1993). A disponibilidade de irrigação diária para o cultivo de $S$. neei no semiárido foi um fator importante para a manutenção do desenvolvimento e brotamento constante de ramos vegetativos.

Para a fenofase de queda foliar, observouse uma maior intensidade deste evento fenológico nas plantas femininas em relação às masculinas no período de julho a novembro de 2014. Os maiores índices de queda foliar foi observado entre os meses de dezembro de 2014 e fevereiro de 2015 $(75 \%)$, os quais não registraram precipitações chuvosas (Figura 3B).

Para Morellato (1991), existe uma relação entre queda de folhas e estacionalidade climática. Em seu estudo na Reserva de Santa Genebra, São Paulo-SP, observou-se que a deficiência hídrica foi o principal fator associado à perda de folhas. Este resultado reforça a observação de que a disponibilidade de recursos hídricos proporcionou boa manutenção da parte aérea da planta, de modo que as maiores porcentagens de queda foliar foram observadas nos meses em que não ocorreram precipitações na área de cultivo.

$\mathrm{O}$ crescimento e o desenvolvimento das plantas são determinados pela combinação de fatores bióticos e abióticos. Para as plantas halófitas em seus ambientes naturais, fatores abióticos como umidade, salinidade, inundação, soterramento por sedimentos, dentre outros, costumam ser os responsáveis por inibir o crescimento das plantas, levando muitas vezes a altas taxas de mortalidade, principalmente nos estágios de estabelecimento (Davy et al., 2000, 2001).

Observou-se que mesmo na área de
cultivo, a $S$. neei apresentou amplo Alves, P. R.; Lucena, E. M. P. de; Bonilla, O. H.; Costa, C. S. B. desenvolvimento de suas estruturas foliares, apesar das condições adversas do ambiente cultivado em relação ao ambiente nativo.

\section{Fenofase reprodutiva: floração}

A floração de $S$. neei teve início no mês de setembro de 2014, totalizando 85 dias após o início do monitoramento, com o maior pico de intensidade desta fenofase ocorrendo no mês de outubro de 2014, tanto para plantas masculinas quanto para as femininas, e perdurando até o mês de abril de 2015.

Os menores índices de floração observados nos indivíduos monitorados ocorreram nos meses com os dias mais longos, entre novembro de 2014 e abril de 2015, e sem precipitação, de dezembro de 2014 a fevereiro de 2015 (Figura 3C).

Foram observados eventos de floração até janeiro de 2015 nas plantas masculinas, e até fevereiro de 2015 nas plantas femininas. O maior índice de floração ocorreu em outubro de 2014 (50\%) tanto para as plantas femininas quanto para as plantas masculinas.

Puente (2003) analisando os aspectos fenológicos da halófita Salicornia bigelovii em cultivo associado com bactérias fixadoras de nitrogênio observou que a mesma atingiu o estágio de floração após 180 dias de cultivo. Sendo esta demanda de tempo superior ao da $S$. neei que atingiu o estádio de floração 120 dias após o cultivo, e 83 dias após a marcação das plantas.

Izeppi (2011) trabalhando com S. neei no litoral do Rio Grande do Sul observou que o cultivo irrigado para geração de biomassa vegetativa é possível na maior parte do ano no litoral gaúcho. Entretanto, a condição climática induz um ciclo fenológico que independente da data de plantio, as plantas apresentam um período de floração de dezembro a maio.

Este período de floração é próximo ao observado em Ocara-CE, mesmo se tratando de uma planta perene em ambiente cultivado, as respostas fenológicas foram semelhantes ao do ambiente nativo.

\section{Frutificação}

A intensidade da fenofase de frutificação ocorreu de modo bastante homogêneo entre os indivíduos monitorados, tanto nas plantas femininas quanto nas plantas masculinas, permanecendo constante tanto nos meses com ocorrência de precipitações, quanto nos meses em que se caracterizou período de estiagem na região,

Alves, P. R., Lucena, E. M. P. de, Bonilla, O. H., Costa, C. S. B. 
sendo observada a frutificação entre os meses de setembro de 2014 até março de 2015.

Esta etapa fenológica também permaneceu sem apresentar diferenças significativas entre os indivíduos monitorados, tanto nas plantas femininas, quanto nas masculinas, ao longo dos períodos em que predominaram os dias com maior duração, bem como nos períodos com dias de menor duração.

A frutificação de $S$. neei foi observada 100 dias após o início do monitoramento, perdurando entre os meses de setembro de 2014 e março de 2015 (Figura 3D).

Amorim et al. (2009), trabalhando com espécies lenhosas da caatinga observaram que as fenofases de floração e frutificação tiveram maior ocorrência durante o período chuvoso, com a floração seguindo o fluxo de folhas e a frutificação se estendendo até o período de queda foliar, embora apenas duas espécies tenham apresentado alguma correlação entre a chuva e essas fenofases. Tais fenofases ocorreram em períodos distintos aos que ocorreram na $S$. neei, que frutificam entre o período seco e início do chuvoso.

Após suas respectivas ocorrências, as fenofases de floração e frutificação predominaram no mesmo período entre as plantas masculinas e femininas monitoradas, devido à presença dos diversos ramos reprodutivos apresentados pelos indivíduos.

\section{Unidades de calor (graus-dia)}

Na Tabela 2 pode se observar os valores das unidades de calor (UC) em ${ }^{\circ} \mathrm{C}$ requeridas pela Salicornia. neei a partir da data da marcação das plantas até o período de amadurecimento dos frutos, caracterizada pela última etapa dos estádios de maturação dos frutos.

Observa-se que até o terceiro estádio reprodutivo $\left(\mathrm{E}_{3}\right)$ de $S$. neei não houve variação significativa das demandas de UC requeridos entre os indivíduos monitorados.
O período reprodutivo desta espécie perene nativa do litoral e cultivada no semiárido cearense teve início no mês de setembro de 2014, e o mesmo durou até o mês de abril de 2015. Esta fenofase reprodutiva foi observada simultaneamente tanto nas plantas femininas, quanto nas plantas masculinas.

Aos 83 dias após marcação (DAM), os botões florais entraram em fase de antese, porém após este período não foi observado o momento da presença do botão floral neste intervalo de tempo. Foram necessárias $1.139,2$ UC para que a $S$. neei pudesse atingir este estádio fenológico (Figuras $4 \mathrm{e}$ 5, Tabela 2).

Aos dez dias após a antese (DAA), observou-se a queda completa das estruturas florais, ocorrendo tanto nas plantas masculinas quanto nas plantas femininas, caracterizando o estádio um $\left(E_{1}\right)$ de frutificação, com a formação completa do fruto, e sendo necessárias 1.282,4 UC para que a planta pudesse atingir este estádio fenológico (Figura 6, Tabela 2).

Aos 16 DAA, sendo necessárias 1.367,3 UC observou-se que os frutos se encontravam no estádio dois $\left(\mathrm{E}_{2}\right)$, tendo início o processo de maturação, com coloração verde escura predominante, e com os segmentos apresentando maior evidência do desenvolvimento das sementes (Figura 7, Tabela 2).

Aos 36 DAA os frutos se encontravam no estádio $3\left(\mathrm{E}_{3}\right)$, devido ao processo de maturação fisiológica dos frutos, os quais apresentavam coloração amarelada predominante. As exigências térmicas requeridas foram de 1.661,8 UC para esta fenofase reprodutiva (Figura 8, Tabela 2).

A última etapa observada ocorreu aos 51 DAA, onde esta fenofase reprodutiva teve seu ciclo completo, com o ressecamento dos frutos para dispersão de sementes. Assim, a soma térmica desde a antese até a maturação dos frutos de $S$ neei foi de 1.885,7 UC (Figura 9, Tabela 2). 

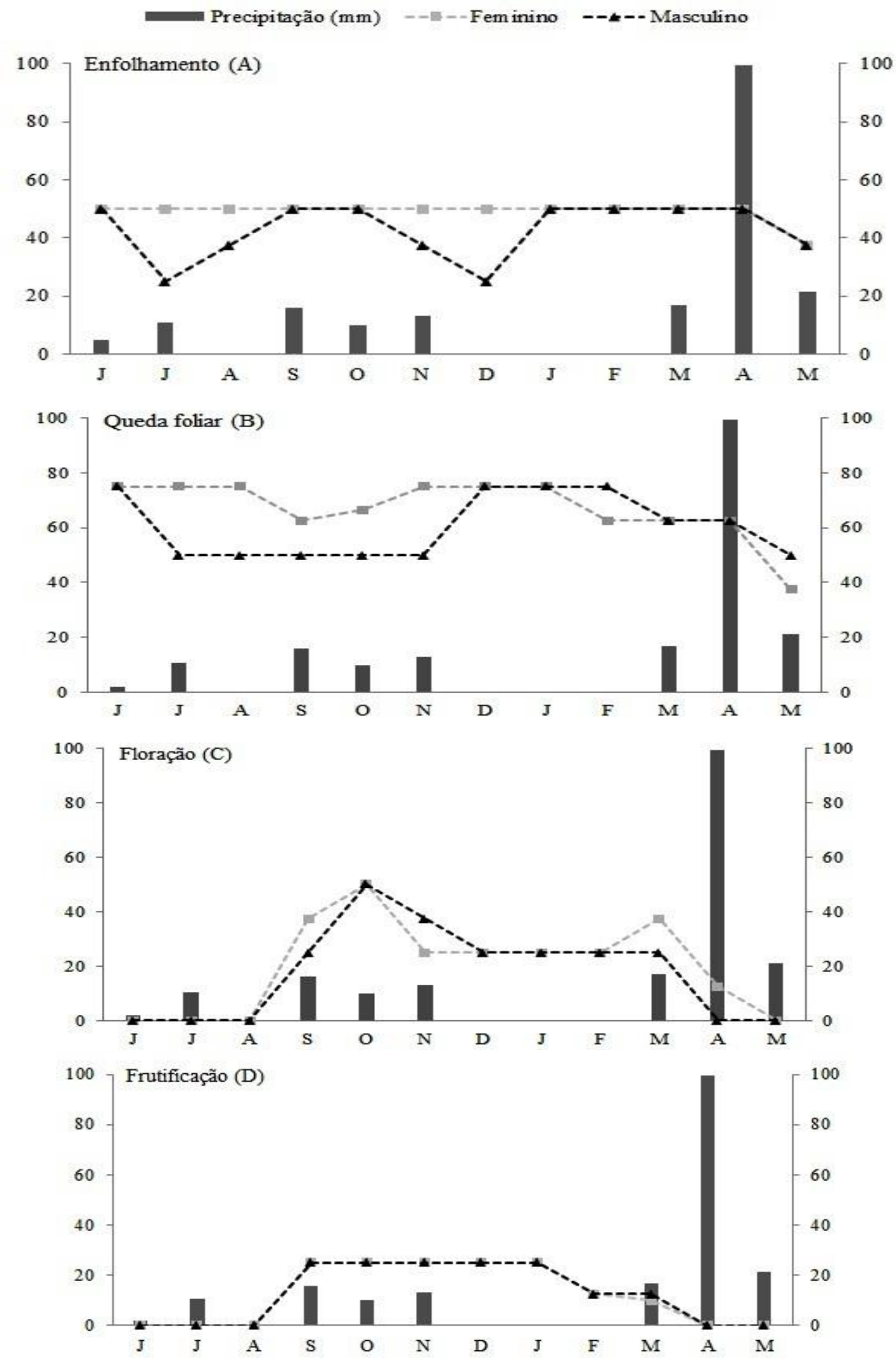

Figura 3. Precipitação pluviométrica e intensidade das fenofases de enfolhamento (A), queda foliar (B), floração (C) e frutificação (D) de Salicornia neei Lag. feminina e masculina, cultivadas no semiárido cearense, de junho/2014 a maio/2015, em Ocara-CE. 
Tabela 2. Unidades de calor (UC) da marcação das plantas até a antese e da antese até o fim da frutificação em Salicornia neei Lag. cultivada no semiárido cearense, de junho/2014 a maio/2015, em Ocara-CE.

\begin{tabular}{llcc}
\hline Fase fenológica & $\mathrm{N}^{\circ}$ de dias & Unidades de calor $\left({ }^{\circ} \mathrm{C}\right)$ & Data do evento \\
\hline Flor em antese & $83(\mathrm{DAM})^{1}$ & $1.139,2$ & $04 / 09 / 2014$ \\
Fruto no estádio 1 $\left(\mathrm{E}_{1}\right)$ & $10(\mathrm{DAA})^{2}$ & $1.282,4$ & $14 / 09 / 2014$ \\
Fruto no estádio 2 $\left(\mathrm{E}_{2}\right)$ & $16(\mathrm{DAA})$ & $1.367,3$ & $20 / 09 / 2016$ \\
Fruto no estádio 3 $\left(\mathrm{E}_{3}\right)$ & $36(\mathrm{DAA})$ & $1.661,8$ & $10 / 10 / 2016$ \\
Fruto no estádio 4 $\left(\mathrm{E}_{4}\right)$ & $51(\mathrm{DAA})$ & $1.885,7$ & $25 / 10 / 2014$ \\
\hline
\end{tabular}

${ }^{1}$ Dias após a marcação; ${ }^{2}$ Dias após a antese.

A $S$. neei necessitou de maior período durante a fase vegetativa, atingindo um valor médio de 82 dias e sendo necessárias 1.124,7 UC, comparado à fase reprodutiva na qual precisou de 51 dias e 1.885,7 UC para concluir essa fenofase.

Por apresentar hábito de crescimento indeterminado, durante a fase reprodutiva, há a ocorrência de uma sobreposição da fase vegetativa, onde, após o início do florescimento a planta continua vegetando (Izzepi, 2011).

Pereira et al. (2010) trabalhando com cultivo de melão em Mossoró, RN, observaram que este cultivo apresentou os valores de graus-dias acumulados do plantio até a primeira colheita do melão, totalizando 415 graus-dias acumulados (GDA) durante o ciclo (52 dias), ou Unidades de Calor (UC).

Oliveira et al. (2009) em cultivo realizado com diferentes cultivares de berinjela, na região de
Seropédica-RJ, observaram valores de graus-dias acumulados do transplantio até a segunda colheita da berinjela, totalizando um período de 416 e 522 graus-dias acumulados (ou Unidades de Calor) para a Ciça e Beriló, respectivamente.

Para a cultura do pimentão, também na localidade de Soropédica, RJ, Pereira, (2006) observou que foram necessários cerca de 1.533 GDA (ou Unidades de Calor) desde o período de transplantio até a última colheita.

Dentre os trabalhos observados nos respectivos autores, somente o cultivo de pimentão apresentou demanda de UC superior ao da S. neei.

Vale salientar que não foram encontrados resultados referentes à cultura da $S$. neei para este tipo de trabalho, uma vez que esta halófita ainda é alvo de pesquisa. 

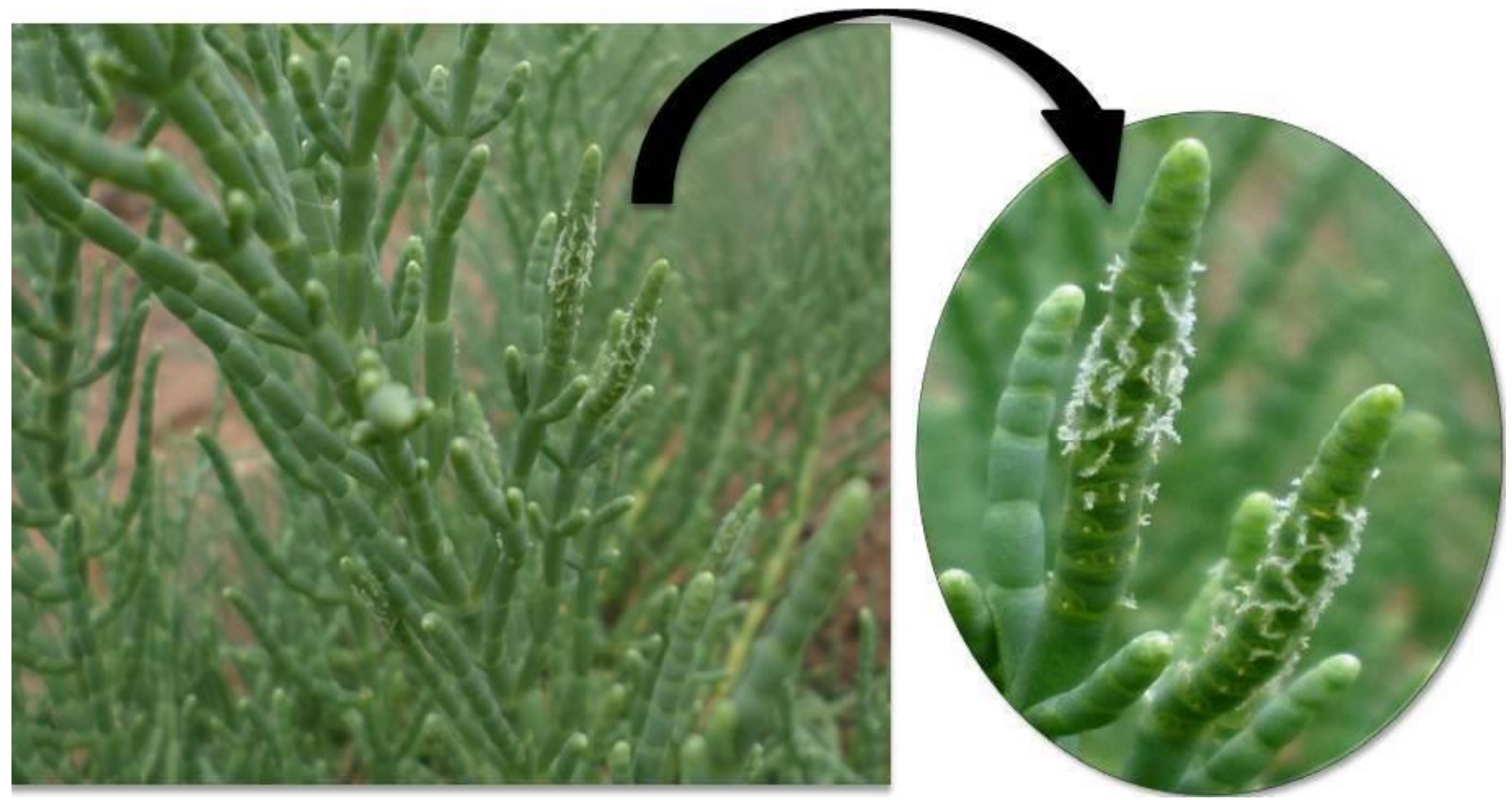

Figura 4. Flor feminina de Salicornia neei Lag. em antese.

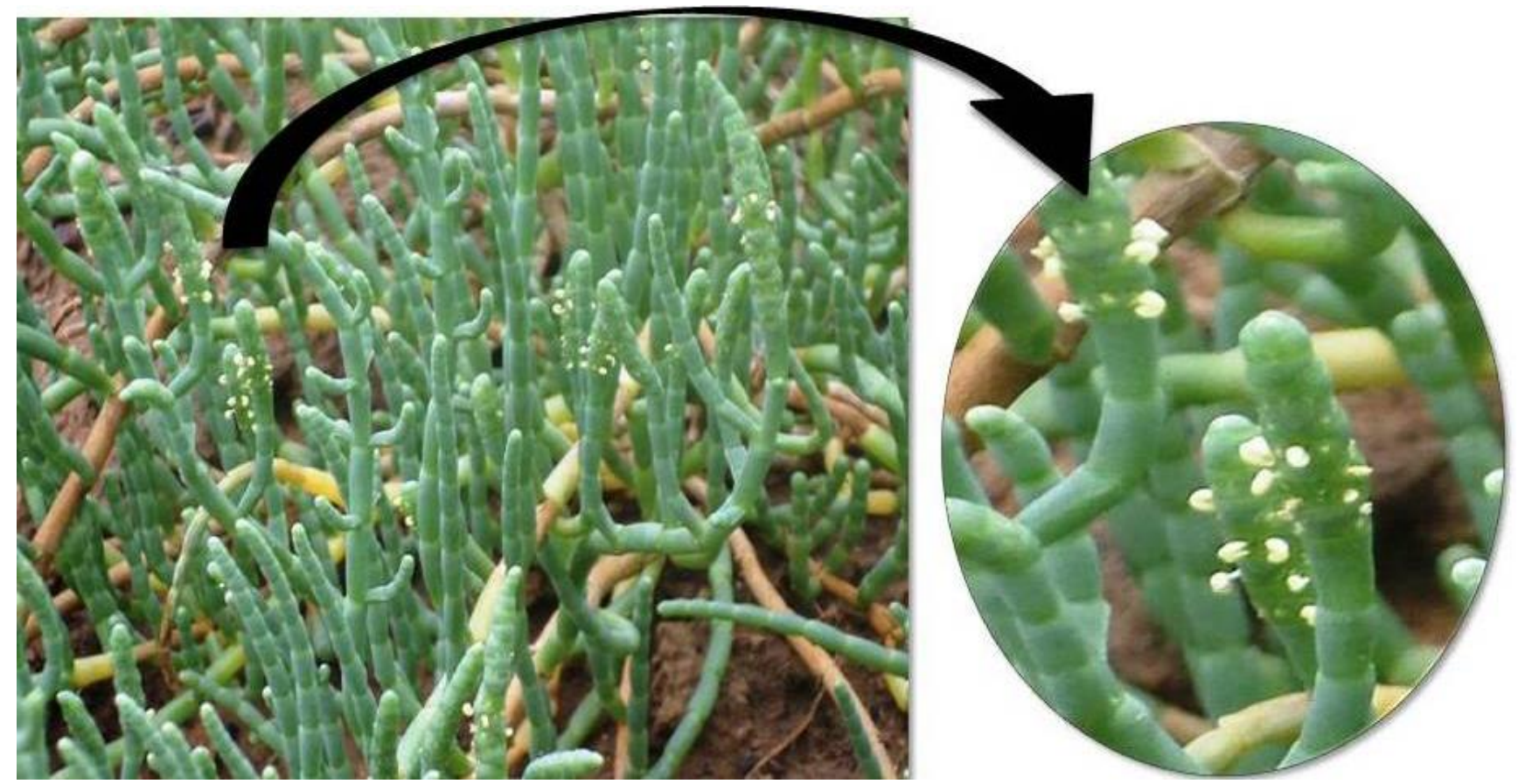

Figura 5. Flor masculina de Salicornia neei Lag. em antese. 
Revista Brasileira de Geografia Física V. 12 N. 02 (2019) 489-504.

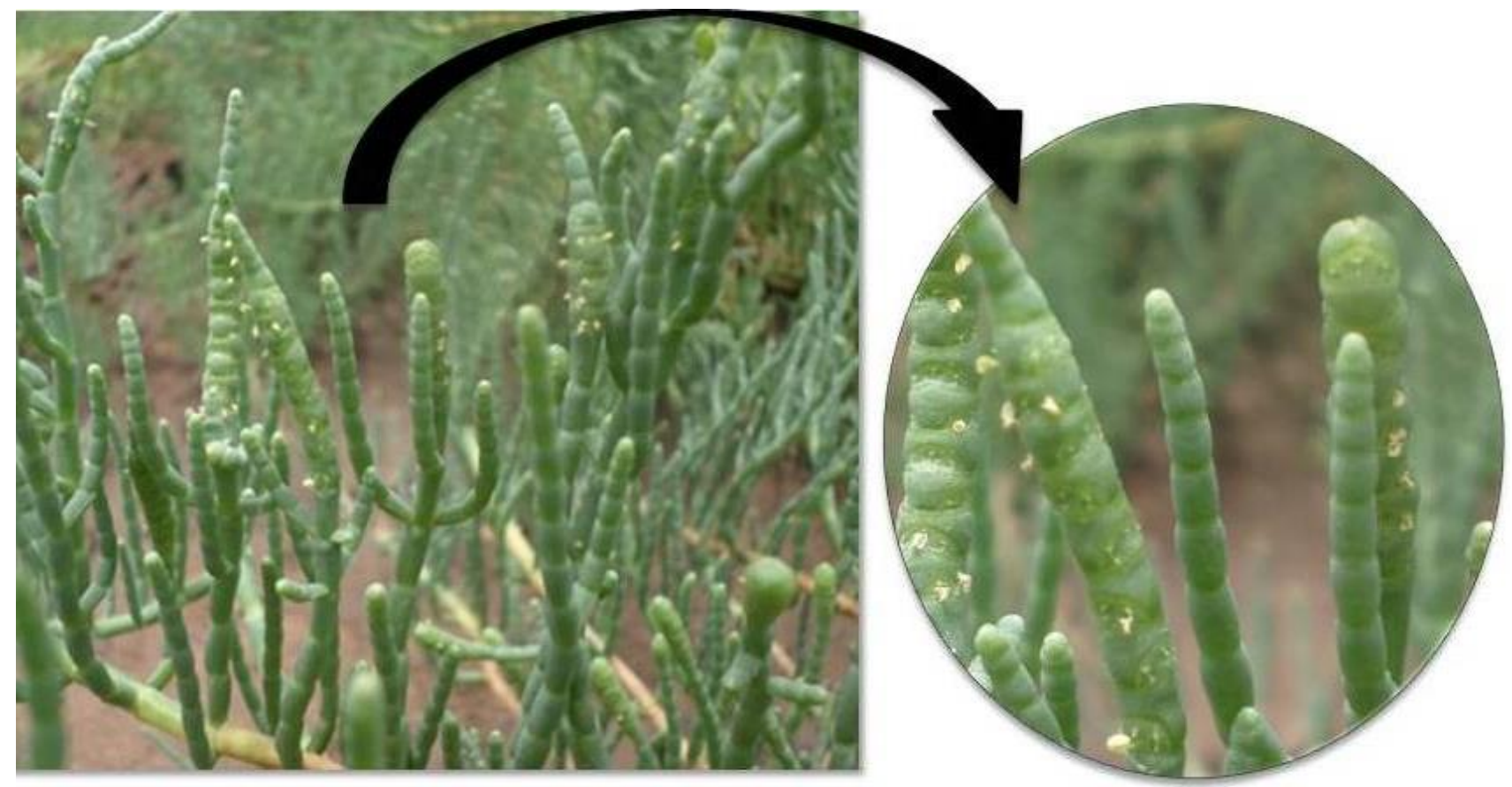

Figura 6. Fruto de Salicornia neei Lag. em estádio $1\left(\mathrm{E}_{1}\right)$, recém formado, com resquícios de estruturas florais e verde-escuro.

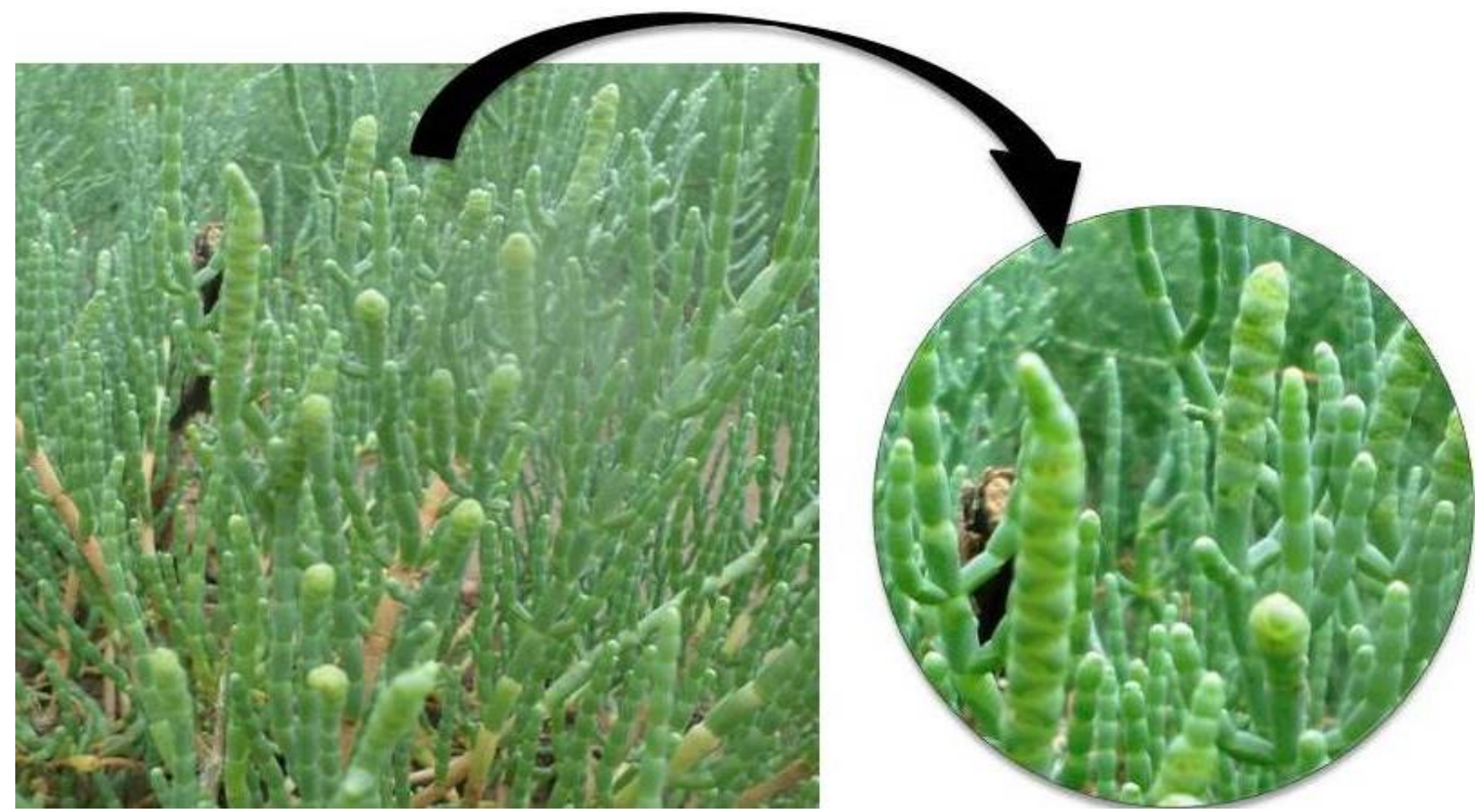

Figura 7. Fruto de Salicornia neei Lag. em estádio $2\left(\mathrm{E}_{2}\right)$, predominância da coloração verde-claro. 


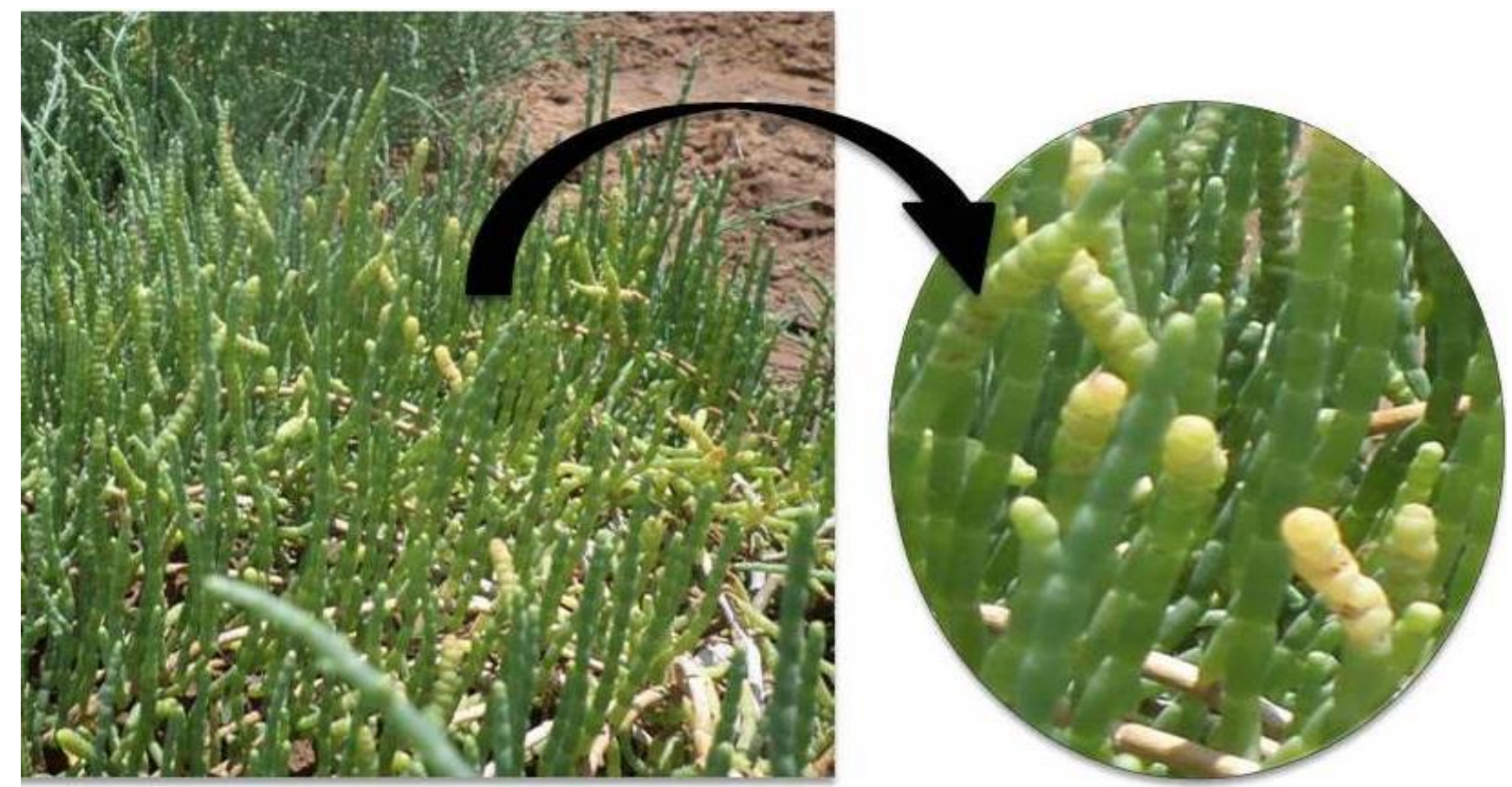

Figura 8. Fruto de Salicornia neei Lag. em estádio $3\left(\mathrm{E}_{3}\right)$, com a coloração amarela.

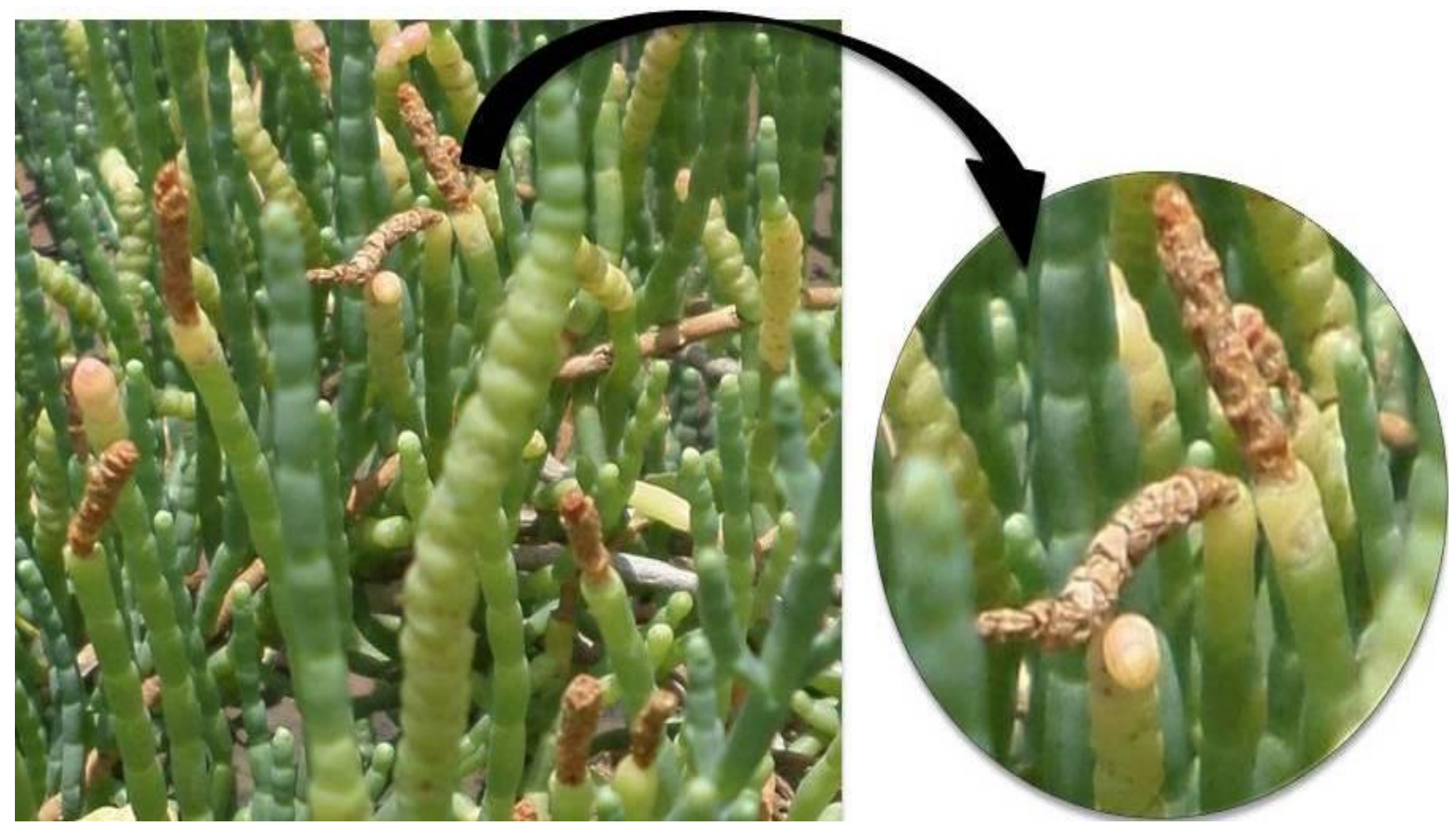

Figura 9. Fruto de Salicornia neei Lag. em estádio $4\left(\mathrm{E}_{4}\right)$, de cor marrom e seco, pronto para dispersão.

\section{Conclusão}

Em função dos resultados obtidos em

1. O brotamento de ramos vegetativos foi constante e presente em todos os indivíduos ambiente de Caatinga, foi possível concluir que: 
masculinos e femininos durante o período monitorado;

2. A queda foliar apresenta baixa intensidade em todos os indivíduos monitorados;

3. A falta de sincronia na floração e frutificação dificulta a colheita das plantas quando maduras, podendo induzir a erros, levando a uma subestimativa na produção de flores e frutos quando estimadas;

4. A halófita litorânea Salicornia neei se adaptou ao clima semiárido no município de Ocara-CE, alcançando todas as fenofases características da espécie;

5. Utilizando a temperatura base $\left(\mathrm{T}_{\text {base }}\right)$ como sendo $15^{\circ} \mathrm{C}$ para a Salicornia neei cultivada no semiárido cearense, os valores da exigência térmica da floração à frutificação foi 1.282,4 unidades de calor (UC).

\section{Agradecimentos}

À Fundação Cearense de Apoio ao Desenvolvimento Científico e Tecnológico (FUNCAP), pela concessão da bolsa de Mestrado do Fundo de Incentivo à Inovação Tecnológica (FIT) ao primeiro autor. Ao Instituto Nacional de Ciência e Tecnologia em Salinidade - INCTsal, pelo apoio financeiro para execução do projeto. À Fundação Cearense de Meteorologia e Recursos Hídricos (FUNCEME) pelo fornecimento dos dados meteorológicos de temperatura e precipitação pluviométrica na área estudada. À Universidade Estadual do Ceará, pela disponibilização do transporte para deslocamento ao local da pesquisa. Ao Sr. Haitzen, proprietário da Fazenda Canafístula no município de Ocara-CE, pelo apoio logístico e disponibilização da área onde ocorreu o cultivo para a referida pesquisa.

\section{Referências}

Alonso, M.A.; Crespo, M.B., 2008. Taxonomic and nomenclatural notes on South American taxa of Sarcocornia A.J. Scott (Chenopodiaceae). Annales Botanici. Fennici 45, 241-254.

Amorim, I.L., Sampaio, E.V.S.B., Araújo, E.L., 2009. Fenologia de espécies lenhosas da caatinga do Seridó, RN. Revista Árvore, Viçosa 33, 491-499.

Bencke, C.S.C., Morellato, L.P.C., 2002. Estudo comparativo da fenologia de nove espécies arbóreas em três tipos de floresta atlântica no sudeste do Brasil. Revista Brasileira de Botânica 25, 237-248.

Berilli, S.S., Oliveira, J.G., Marinho, A.B., Lyra, G.B., Sousa, E.F., Viana, A.P., Bernardo, S., Pereira, M.G., 2007. Avaliação da taxa de crescimento de frutos de mamão (Caricapapaya L.) em função das épocas do ano e graus-dias acumulados. Revista Brasileira de Fruticultura 29, 11-14.

Bertin, R.L., Gonzaga, L.V., Borges, G.S.C., Azevedo, M.S., Maltez, H.F., Heller, M., Micke, G.A., Tavares, L.B.B., Fett, R., 2014. Nutrient composition and, identification/ quantification of major phenolic compounds in Sarcocornia ambígua (Amaranthaceae) using HPLC-ESI-MS/MS. Food Research International 55, 404- 411.

Bertin, R.L., Maltez, H.F., Gois, J.S., Borges, D.L.G., Borges, G.S.C., Gonzaga, L.V., Fett, R., 2016. Mineral composition and bioaccessibility in Sarcocornia ambigua using ICP-MS, Journal of Food Composition and Analysis.47, 45-51.

Busato, C.C.M., Soares, A.A., Motoike, S.Y., Busato, C., 2013. Fenologia e exigência térmica da cultivar de videira 'Niágara Rosada' produzida no Noroeste do Espírito Santo. Revista Trópica: Ciências Agrárias e Biológicas 7, 135-148.

Costa, C.S.B., Neves, L.S., 2006. Respostas Cromaticas de Salicornia gaudichaudiana Mog. (Chenopodiaceae) a diferentes níveis de radiação UV-B e salinidade. Atlântica. Rio Grande 28, 25-31.

Costa, C.S.B., 2011. Restoration of coastal salt marshes in Brazil using native salt marsh plants. In: Restoration Ecology (Greipsson, S. ed). Jones and Bartlett Publishers, Sudbury (MA. U.S.A.) 333-338.

Costa, C.S.B., Vicenti, J.R.M., Moron-Villareyes, J.A., Caldas, S.; Cardozo, L.V., Freitas, R.F., D’Oca, M.G.M., 2014. Extractionand characterization of lipids from Sarcocornia ambigua meal: A halophyte biomass produced with shrimp farm effluent irrigation. Anais da Academia Brasileira de Ciências 86, 935-943.

Costa, C.S.B., Herrera, O.B., 2016. Halophytic life in Brazilian salt flats: Biodiversity, uses and threats. In: Khan, M.A., Boër, B., Ozturk, M., Clüsener-Godt, M., Gul, B.; Breckle, S.-W. (ed.) Sabkha Ecosystem V: The Americas. Berlin: Springer, 11-27.

Costa, C.S.B., Chaves, F.C., Rombaldi, C.V., Souza, C.R., 2018. Bioactive compounds and antioxidant activity of three biotypes of the sea asparagus Sarcocornia ambigua (Michx.) M.A.Alonso \& M.B.Crespo: A halophytic crop for cultivation with shrimp farm effluent. S. Afr. J. Bot. 117, 95-100.

Chitarra, M.I.F., Chitarra, A.B., 2005. Pós-colheita de frutas e hortaliças: fisiologia e manuseio, 2. ed. UFLA, Lavras. 
D'oca, M.G.M. et al. 2012. Fatty acids composition in seeds of the South American glasswort Sarcocornia ambigua. Annals of the Brazilian Academy of Sciences 84, $245-261$.

Davy, A.J., Costa, C.S.B., Proudfoot, A.M., Yaloop, A.R., Mohamed, M., 2000. Biotic Interactions In Plant Communities of Saltmarshes. In: Sherwook, B.R., Gardiner, T.G., Harris, B.R. (Org.). British Salthmarshes. 1 ed. Ceredgion (Inglaterra): Linnean Society/ Forrest Text, $109-127$.

Davy, A.J., Bishop, G.F., Costa, C.S.B., 2001. Salicornia L. (Salicornia pusilla J. Woods, S. ramosíssima J. Woods, $S$. europea L., $S$. obscura P.W. Ball \&Tutin, S. nitens P.W. Ball \&Tutin, S. fragilis P.W. Ball \&Tutin and S. dolichostachya Moss). Journal of Ecology, 681707.

Doncato, K.B., Costa, C.S.B., 2017. Growth and mineral composition of two lineages of the sea asparagus Sarcocornia ambigua irrigated with shrimp farm saline effluent. Exp. Agric. 54, 399-416.

Ferreira, C. A., Torezan-Silingardi, M., 2013. Fenologia, morfologia floral e visitantes florais de duas espécies do gênero Banisteriopsis (Malpighiaceae) em uma reserva de Cerrado. Dissertação (Mestrado em Ecologia e Conservação de Recursos Naturais) - Instituto de Biologia, Universidade Federal de Uberlândia, Uberlândia.

Fournier, L.A., 1974. Um método cuantitativo para la medición de características fenológicas enarboles. Turrialba, Turrialba 24, 422-424.

Freire, M.B.G., Souza, E.R., Freire, F.J. Fitorremediação de solos afetados por sais. In: Gheyi, H.R.; Dias, N.S.; Lacerda, C.F., 2010. Manejo da salinidade na agricultura. Fortaleza, INCT Sal, 472p.

Greis, G., 2009. Cultivo de Salicornia gaudichaudiana Moq. irrigada com efluente de camarão no clima temperado na costa sul do Brasil. Dissertação de Mestrado, Programa de Pós-graduação em Oceanografia Biológica. Universidade Federal do Rio Grande - FURG, Rio Grande, RS.

IPECE. Instituto de Pesquisa e Estratégia Econômica do Ceará, 2015. Perfil básico municipal 2015: Ocara. SEPLAG, Fortaleza. Disponível:

http://www.ipece.ce.gov.br/publicacoes/perfil_ basico/pbm-2015/Ocara.pdf. Acesso: 14 nov. 2016.

IPECE. Instituto de Pesquisa e Estratégia Econômica do Ceará, 2016. Ceará em mapas: limites municipais e distritais região de planejamento Maciço de Baturité - 2016.
SEPLAG, Fortaleza. Disponível: http://www2.ipece.ce.gov.br/atlas/capitulo1/11 /pdf/Distritos_Baturite.pdf. Acesso: 14 nov. 2016.

Izeppi, E.M., 2011. Efeitos da densidade de plantio na sobrevivência, desenvolvimento e produção de biomassa da halófitas Sarcocornia ambígua (Michx.) Alonso \& Crespo. Dissertação 70 f., Instituto de Oceanografia, Universidade Federal do Rio Grande - FURG, Rio Grande, RS.

Leite, M.S., Barros, F.J.A., Khoury, S.H., Bonilla, O.H., Costa, C.S.B., 2007. Cultivo de Plântulas de Salicornia gaudichaudiana Moq. para uso em Bioremediação junto a Viveiros de Criação de Camarão. Revista Brasileira de Biociências, Porto Alegre 5, 297-299.

Lucena, E.M.P. de, 2006. Desenvolvimento e maturidade fisiológica de manga 'Tommy Atkins' no vale do São Francisco. Tese (Doutorado em Agronomia/Fitotecnia). Fortaleza, Universidade Federal do Ceará.

Martins, F.B., Reis, D.F.da., Pinheiro, M.V.M., 2012. Temperatura base e filocrono em duas cultivares de oliveira. Ciência Rural 42, 19751981.

Morellato, L.P.C., 1991. Estudo da fenologia de árvores, arbustos e lianas de uma floresta semidecídua no sudeste do Brasil. Tese de Doutorado, Universidade de Campinas, Campinas, São Paulo.

Muniz, L.F., Pereira, J.M.R., Ximenes Junior, C.L., Studar, T.M.C., 2017. Classificação climática para o estado do ceará Utilizando distintos sistemas de caracterização. In: Anais do XXII Simpósio Brasileiro de Recursos Hídricos. Florianópolis, SC. $1-8$.

Müller, L., Manfron, P.A., Medeiros, S.L.P., Streck, N.A., Mittelmman, A., Neto, D.D., Bandeira, A.H., Morais, K.P., 2009. Temperatura base inferior e estacionalidade de produção de genótipos diploides e tetraploides de azevém. Ciência Rural 5, 1343-1348.

Nielsen, A.L., Chen, S., Fleischer, S.J., 2016. Coupling developmental physiology, photoperiod and temperature to model phenology and dynamics of an invasive heteropteran, Halyomorphahalys. Frontiers in Physiology 7, 1 - 4 .

Oliveira, A.D. de. et al., 2009. Graus dias acumulados para a berinjela em Seropédica-RJ. XVI Congresso Brasileiro de Agrometeorologia. Anais... Belo Horizonte, MG., CD Rom. Disponível: http://www.sbagro.org.br/anais_congresso_200 9/cba2009/033.pdf

Parida, A.K., Jha, B., 2010. Antioxidative defense potential to salinity in the Euhalophyte 
Salicornia brachiata. Journal of Plant Grown Regulation 29, 137-148.

Pereira, V. da. C., Vieira, R.Y.M., Espínola Sobrinho, J., Oliveira, A.D. de., Cavalcante Junior, E.G., Almeida, B.M. de., Borges, V.P., Silva, F.G. da., Oliveira, I.A. de., 2010. Grausdias acumulados e índice de área foliar para a cultura do melão em Mossoró-RN. XVI Congresso Brasileiro de Meteorologia. Anais... Belém do Pará, PA. CD Rom. Disponível: http://www.sbmet.org.br/cbmet2010/artigos/11 6_46462.pdf

Pereira, J.B.A., 2006. Avaliação do Crescimento, Necessidade Hídrica e Eficiência no Uso da Água pela Cultura do Pimentão (Capsicum Annuum. L), sob Manejo Orgânico nos Sistemas de Plantio com Preparo do Solo e Direto - Seropédica, RJ. Dissertação (Mestrado). Seropédica, Universidade Federal Rural do Rio de Janeiro.

Porto, E.R., Amorin, M.C.C., Dutra, M.T.D., Paulino, R.V., Brito, L.T.L., Matos, A.N.B., 2006. Rendimento da Atriplex numularia irrigada com efluentes da criação de tilápia em rejeito da dessalinização de água. Revista Brasileira de Engenharia Agrícola e Ambiental 10, 97-103.

Puente, E.O.R., 2003. Estudio de lafenología y potencial productivo de lahalofita Salicornia bigelovii (Torr.) com la asociación de bactérias fijadoras de nitrógeno. Playa Palo de Santa Rita Sur La Paz, B.C.S. México. Tese (Doutorado). Centro de Investigaciones Biológicas del Noroeste, S.C.

Roberto, S.R., Sato, A.J., Brenner, E.A., Jubileu, B.S., Santos, C.E.S., Genta, W., 2005. Caracterização da fenologia e exigência térmica (graus-dias) para uva 'Cabernet Sauvignon' em zona subtropical. Acta Scientiarum. Agronomy 27, 183-187.
Rosa, H.T., Walter, L.C., Streck, N.A., Alberto, C.M., 2009. Métodos de soma térmica e datas de semeadura na determinação de filocrono de cultivares de trigo. Pesquisa Agropecuária Brasileira 44, 1374-1382.

Ruana, C.J., Lia, H., Guob, Y.Q., Qinb, P., Gallagherc, J.L., Seliskarc, D.M., Luttsd, S., Mahye, G., 2008. Kosteletzkya virginica, an agroecoengineering halophytic species for alternative agricultural production in China's east coast: Ecological adaptation and benefits, seed yield, oil content, fatty acid and biodiesel properties. Ecological Engineering 32, 320-328.

Scoriza, R.N., Piña-Rodrigues, F.C.M., 2014. Influência da precipitação e temperatura do ar na produção de serapilheira em trecho de floresta estacional em Sorocaba, SP. FLORESTA 44, 687 - 696. Disponível: http://dx.doi.org/10.5380/rf.v44i4.34274. doi.org/10.5380/rf.v44i4.34274.

Taiz, L., Zeiger, E., 2013. Fisiologia Vegetal. 5.ed. Porto Alegre: Artmed, 954p.

TROPICOS. Tropicos.org. Missouri Botanical Garden, 2019. Disponível em: < http://www.tropicos.org/NamePage.aspx?name $\mathrm{id}=7200300>$. Acesso em: 16 jan 2019.

Timm, T.G., Silva Jr., A.A., Bertin, R.L., Tavares, L.B.B., 2015. Processamento de conservas de Sarcocornia perennis. Agropecuaria Catarinense 28, 97-102.

Tubelis, A., Nascimento, F.J.L., 1992. Meteorologia descritiva: fundamentos e aplicações brasileiras. Nobel, São Paulo.

Van Schaik, J.W., Terborgh, S.J., 1993. The phenology of tropical forests: Adaptive significance and consequences for primary consumers. Annual Review of Ecology and Systematics 24, 353-377. 